\title{
Akrasia e errância da vontade em Schopenhauer
}

\author{
Akrasia and the errancy of the will in Schopenhauer
}

\author{
Bruno Wagner Santana \\ Doutorando em Filosofia pela PUC-RJ \\ E-mail: brunowagnersou@yahoo.com.br
}

\begin{abstract}
Resumo: Partindo do que Schopenhauer considera ser o pressuposto de toda ética, a significação interior do mundo, isto é, a diversidade que vige nas ações humanas entre a causalidade interior e a materialidade do mundo, o presente artigo recorre inicialmente à Crítica da filosofia kantiana, onde Schopenhauer afirma que Kant operou na filosofia a maior de todas as revoluções ao instaurar uma descontinuidade entre o ideal e o real, insurgindo-se assim contra o realismo filosófico, substituindo a crença na potência do intelecto pela noção de fantasia e incluindo o fator subjetivo dentre as causas da variação de humor. Mas para além do mundo mediado pela subjetividade há o mundo como vontade, onde se desenha a história trágico-cômica do mundo: a vontade não se move em direção a um objeto que justifique seu desgaste, que a recompense proporcionalmente ao esforço realizado e garanta-lhe a satisfação esperada.
\end{abstract}

Palavras-chave: Vontade; Descontinuidade; Fantasia.

Abstract: Starting from that which Schopenhauer considers the assumption of all ethics, the inner meaning of the world, i.e., the upon human action prevailing diversity between the inner causality and the materiality of the world, this article firstly treats Schopenhauer's critique on Kant's philosophy, in which Schopenhauer affirms that Kant has contributed to philosophy above all the discontinuity between the ideal and the real, by substituting the belief in the power of the intellect by the notion of fantasy and including the factor of subjectivity among the causes of mood swings. Secondly, it discusses the world as will opposed the world of subjectivity.Here the tragic comic story of the world unfolds, because the will does not move towards an object justifying the world's wear, proportionally rewarding the efforts that are made or guarantying the expected satisfaction.

Keywords: Will; Discontinuity; Fantasy.

Apreender o pensamento de um filósofo requer, antes de mais nada, procurar perceber aonde ele coloca seu ponto de interrogação, o problema que o põe em marcha. Segundo Nietzsche, a grandeza de Schopenhauer esteve em colocar a questão sobre o valor da existência em primeiro plano, problema que decide acerca do querer ou não querer a vida ${ }^{1}$, isto é, afirmá-la ou negá-la, o que mostra que a questão fundamental de

\footnotetext{
${ }^{1}$ SCHOPENHAUER, A. WWV/MVR I, §56, p.390.
} 
Schopenhauer incide sobre o querer, e que o conhecimento nele ocupa uma importância secundária em relação à vontade.

De todas essas considerações ressalta claramente que o querer-viver não é uma consequência do conhecimento da vida, nem de alguma maneira uma conclusão exproemissis, nem, de maneira geral, algo secundário; ao contrário, ele é o princípio primeiro e absoluto, e merece por isso se tornar o ponto de partida da filosofia; pois não é o querer-viver que aparece como uma consequência do mundo, é o mundo que é produzido como uma consequência da vontade de viver. ${ }^{2}$

A vida nela mesma é ilimitada ${ }^{3}$, fluxo perpétuo da matéria ${ }^{4}$, mas a vida em sua dimensão física, material, ilimitada e infinita, não basta para responder à questão sobre o valor da existência, pois quem poderia falar em nome da vida por ela mesma, em todas as suas perspectivas? Como diz Nietzsche, o valor da vida não poderia ser estimado por um vivente senão enquanto sintoma de um querer particular $^{5}$, já que ele é parte interessada nessa disputa, de maneira que um juízo que pretenda expressar o valor da vida em geral, em si, constitui uma presunção. Corroborando com essa afirmação de Nietzsche, o pressuposto primeiro de toda ética consiste, segundo Schopenhauer, na significação interior $^{6}$ do mundo, isto é, na diferenciação e diversidade entre o ideal e o real; verdades físicas podem possuir muita significação exterior, mas carecem de significação interior, tal como o magnetismo, a termoeletricidade ou a gravidade não determinam as diversas manifestações da atividade humana. Achar

que o mundo possui apenas uma significação física, e nenhuma moral, constitui o maior, o mais condenável, e o mais fundamental erro, a própria perversidade da mentalidade ${ }^{7}$.

Exemplo da diversidade que vige nas ações humanas entre a causalidade interior e a materialidade do mundo, dentre inúmeros exemplos possíveis, é o suicídio.

No homem nem a felicidade nem o humor melancólico são determinados por circunstâncias exteriores, como a riqueza ou a

\footnotetext{
${ }^{2}$ SCHOPENHAUER, A. WWV/MVR, II, "Caractère du vouloir-vivre", p. 1087.

${ }^{3}$ SCHOPENHAUER, A. WWV/MVR, I, §54, p. 356.

${ }^{4}$ SCHOPENHAUER, A. WWV/MVR, I, §54, p.352.

${ }^{5}$ NIETZSCHE, F. Crepúsculo dos ídolos, "O problema de Sócrates", §2, p. 18.

${ }^{6}$ SCHOPENHAUER, A. P/P, §108, p. 188.

${ }^{7}$ SCHOPENHAUER, A. P/P, §109, p. 188.
} 
situação no mundo. (...) Veja então os suicidas; quantas causas diversas eles não têm! Não há uma só infelicidade, tão grande quanto ela seja, da qual possamos dizer com alguma verossimilhança que tenha sido para todos os homens, qualquer que fosse seu caráter, uma razão suficiente para se matar. ${ }^{8}$

Muitas vezes a tristeza é determinada por nossas relações exteriores, é verdade; mas ocorre com frequência que nessas situações figuramos que bastaria suprimir essa causa exterior que nos perturba para adentrarmos no reino da "alegria mais perfeita. Pura ilusão!"9. Seguindo esse pensamento de que eliminando nossas relações exteriores eliminamos tudo o que nos é fonte de desprazer e incômodo, o suicídio se faz um ato inútil $^{10}$, pois é incapaz de se libertar da insatisfação e da dor ${ }^{11}$, tal como a doença de um indivíduo não faz da natureza algo mais doente ou menos doente ${ }^{12}$, mas apenas a ele indiferente. O sentimento interior confuso diante da dor, da insatisfação e da morte, ao invés de envenenar a vontade de viver, deve antes servir como "princípio dessa energia que anima e redirige tudo o que tem vida e o torna tão alegre como se a morte não estivesse em lugar nenhum"13. A variação do nosso humor, alegre ou sombrio, não deve ser atribuída à variação do tempo e circunstâncias externas, mas a variações de nosso estado interior. ${ }^{14}$

Frequentemente nos desviamos, como de uma medicina amarga, dessa verdade, que o sofrer é a essência mesma da vida; que desde então o sofrimento não se infiltra em nós vindo de fora, que trazemos em nós mesmos a fonte infindável de onde ele provém. Essa dificuldade que é inseparável de nós, ao contrário nós estamos sempre a procurar para ela uma causa externa, e como um pretexto; de maneira semelhante ao homem livre que ergue um ídolo para não ficar sem mestre. Sem nos cansar, corremos de desejo em desejo; em vão cada satisfação obtida, a despeito do que ela prometia, não nos satisfaz e muitas vezes não nos deixa senão a lembrança de um erro vergonhoso; continuamos a não compreender, recomeçamos o jogo das Danaides; e eis que mais uma vez estamos perseguindo novos desejos. ${ }^{15}$

\footnotetext{
${ }^{8}$ SCHOPENHAUER, A. WWV/MVR, I,\$57, p. 400.

${ }^{9}$ SCHOPENHAUER, A. WWV/MVR, I, $\$ 57$, p. 400.

${ }^{10}$ SCHOPENHAUER, A. WWV/MVR, I,§54, p. 358.

${ }^{11}$ SCHOPENHAUER, A. WWV/MVR, I,§54, p. 357.

${ }^{12}$ SCHOPENHAUER, A. WWV/MVR, I, $\$ 54$, p. 351.

${ }^{13}$ SCHOPENHAUER, A. WWV/MVR, I, $\$ 54$, p. 360.

${ }^{14}$ SCHOPENHAUER, A. WWV/MVR, I,\$57, p. 400.

${ }^{15}$ SCHOPENHAUER, A. WWV/MVR, I,\$57, p. 402. 
A diversidade entre a causalidade exterior e a significação interior não é algo que se pode ver apenas em determinadas ações humanas, mas é algo pressuposto em toda moral na medida em que a realidade externa se faz realidade mediada por inteirações e comparações com o outro:A consciência moral acompanha toda a ação com o comentário: "Tu também poderias agir de outro modo", embora seu verdadeiro

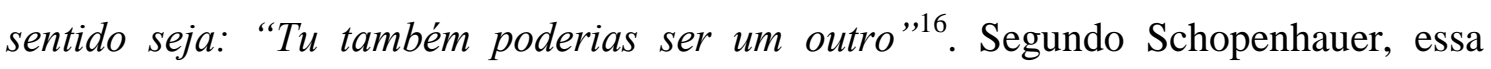
diversidade entre causalidade material, externa, e causalidade interna, entre o real e o ideal, teve sua condição de surgimento na distinção kantiana entre fenômeno e coisa em si; essa distinção fora mesmo o grande mérito de $\mathrm{Kant}^{17}$.

Antes de Kant, as leis dos fenômenos eram tomadas como verdades eternas, de maneira que bastava observá-los para descobrir a realidade no seu âmago mais essencial e verdadeiro. Esse realismo filosófico, anterior a Kant,procurou erigir, sobre essas leis consideradas absolutas, valores morais considerados eternos, isto é, buscaram encontrar em tais leis julgadas absolutas o fundamento para uma teoria da beatitude, para a noção de verdades eternas, para uma teoria sobre Deus... O que norteava esse realismo filosófico era o conceito de perfeiçãa $o^{18}$, termo esse que não é senão um sinônimo de "completo", ou seja, uma coisa qualquer era considerada perfeita desde que nela se encontrassem todos os predicados contidos na definição de sua essência. O conceito de perfeição assim não possuía nenhum conteúdo positivo e funcionava antes como uma espécie de signo algébrico, uma palavra vazia e abstrataque designa não um conteúdo propriamente, mas uma relação entre atributos. Dessa forma é que a moral antes de Kant girava sempre em torno do conceito de perfeição e imperfeição ${ }^{19}$.

Kant abalou essa maneira de se pensar a moral - maneira essa que se fiava na crença do poder do intelecto de apreender e determinar o mundo em sua essência, em sua verdade eterna - quando separou o campo da moral do campo do conhecimento; o campo do conhecimento estando limitado a investigar agora a dimensão dos fenômenos, isto é, do espaço e do tempo, enquanto o campo da moral tocaria um domínio para além do espaço e do tempo, domínio da coisa-em-si ${ }^{20}$. A distinção feita por Kant entre esses

\footnotetext{
${ }^{16}$ SCHOPENHAUER, A. P/P, §118, p. 212.

${ }^{17}$ SCHOPENHAUER, A. KK/CK, p.522.

${ }^{18}$ SCHOPENHAUER, A. KK/CK, p. 531.

${ }^{19}$ SCHOPENHAUER, A. KK/CK, p. 532.

${ }^{20}$ SCHOPENHAUER, A. KK/CK, p. 532.
} 
dois campos de investigação, campo do conhecimento e campo da moral, decorreu da distinção feita também por ele entre fenômeno e coisa-em-si, distinção essa que "operou na filosofia a maior revolução de todos os tempos"21. Segundo Kant, não temos um acesso direto e imediato à realidade em sua essência, pois entre nós e as coisas há o entendimento $^{22}$.

Kant provou que essas leis [leis dos fenômenos], e consequentemente o mundo nele mesmo, são condicionados pela faculdade de conhecer do sujeito; portanto, é evidente que tomando tais leis por guias (...) não avançamos senão um passo quanto à questão capital, jamais chegamos a saber o que é o ser do mundo em si, fora da representação. $^{23}$

Aonde antes era visto uma continuidade entre o ideal e o real, entre o intelecto e as essências das coisas, Kant interpôs um muro ${ }^{24}$, muro da representação, ao afirmar que todo o conhecimento que temos do mundo tem por condição nossa subjetividade, isto é, encontra-se mediado pela faculdade de conhecer de uma subjetividade finita e pistemologicamente. Com isso, segundo Schopenhauer, Kant "iluminou uma importante verdade, a saber, que o fim e o começo do mundo devem ser procurados não fora de nós, mas em nós mesmos" 25 . Com isso, Kant quis dizer que, por exemplo, não conhecemos nem o sol nem a terra neles mesmos, mas mediados por nossos órgãos e faculdades: temos um olho que vê o sol e uma mão que sente a terra."Entre as coisas e nós, há sempre o entendimento, o entendimento que os impede de serem conhecidos tal como eles podem ser em si”.

O mérito capital da filosofia de Kant foi, segundo Schopenhauer, ao criticar a crença de que conhecemos o mundo em si, ter demonstrado racionalmente que a base de toda a nossa relação com o mundo é a ilusão ${ }^{26}$ - "Maya", para os hindus -, ilusão essa “em virtude da qual se joga essa comédia fantástica que chamamos de mundo exterior" ${ }^{27}$; em lugar da potência do intelecto, da crença na potência infinita da intuição

\footnotetext{
${ }^{21}$ SCHOPENHAUER, A. KK/CK, p. 532.

${ }^{22}$ SCHOPENHAUER, A. KK/CK, p. 522.

${ }^{23}$ SCHOPENHAUER, A. KK/CK, p. 526.

${ }^{24}$ SCHOPENHAUER, A. KK/CK, p. 528.

${ }^{25}$ SCHOPENHAUER, A. KK/CK, p. 526.

${ }^{26}$ SCHOPENHAUER, A. KK/CK, p. 525.

${ }^{27}$ SCHOPENHAUER, A. KK/CK, p. 525.
} 
intelectual de conhecer as coisas na sua essência mais íntima, Kant substitui-a pela noção de fantasia ${ }^{28}$. Afirmando que não conhecemos o mundo fora da representação, mas apenas mediados pela nossa subjetividade, a filosofia de Kant teve um efeito negativo: uma incerteza radical, uma crise do conhecimento, um sentimento de vazio e inquietude $^{29}$. É sob esse aspecto, em que não podemos ter um conhecimento imediato do real, mas apenas mediado pela nossa subjetividade, é sob esse aspecto que Schopenhauer entende o mundo como sendo representação.

No entanto, para Schopenhauer temos acesso também a um mundo que está para além da representação, isto é, para além da razão e da consciência, para além do princípio de razão suficiente, princípio esse quelê o mundo a partir da lei de causalidade $^{30}$. Segundo Schopenhauer, temos acesso também ao aspecto em-si do mundo, acesso esse que nos é dado por meio de nosso corpo, por meio dos movimentos e impulsos do nosso corpo. O mundo como representação é um mundo mediado pela representação e ordenado pelas categorias do espaço, do tempo e pela lei de causalidade, ou seja, um mundo que é objeto para um sujeito; mas Schopenhauer não considera a representação do fenômeno como sendo a única realidade cognoscível, como fez Kant. O homem, segundo Schopenhauer, não é apenas representação, mas também corpo, e a este temos acesso de duas maneiras: como representação, isto é, como sendo mais um objeto dentre outros, mais um fenômeno dentre outros; e também como realidade imediata percebida nos movimentos de nosso corpo, ou seja, como "vontade". Esse conhecimento imediato do corpo como sendo vontade decorre do fato de que todo ato real de nossa vontade implica necessariamente no movimento do corpo, de modo que o sujeito não pode querer efetivamente sem constatar ao mesmo tempo o movimento de seu corpo - o ato volitivo e a ação do corpo são uma só e mesma coisa, e é por meio do corpo que sentimos que vivemos, que experimentamos sensações de prazer e dor, onde se manifesta mais explicitamente o anseio de viver de cada indivíduo, isto é, o impulso à conservação presente em toda a natureza. O corpo é dessa forma a via pela qual sentimos e experimentamos o mundo como não sendo um objeto de conhecimento, mas como algo independente do intelecto, momento esse em que,

\footnotetext{
${ }^{28}$ SCHOPENHAUER, A. KK/CK,p.526.

${ }^{29}$ SCHOPENHAUER, A. KK/CK,p.533.

${ }^{30}$ SCHOPENHAUER, A. SG/PR, p.44, apud BRUM, Thomaz. O pessimismo e suas vontades, p.21.
} 
segundo Schopenhauer, sentimos que a essência íntima de todo fenômeno e de todo nosso ser nada mais é do que vontade, impulso cego e irracional. Como se pode notar, "o subjetivo nos fornece aqui a chave de interpretação do objetivo"31.

Tomando consciência da vontade, nós tomamos consciência do que constitui a expressão mais íntima do mundo, onde tudo se apressa e se impulsiona rumo à existência ${ }^{32}$, por exemplo, na força que faz crescer as plantas e que dá forma ao cristal, nas forças de atração e repulsão presentes na natureza... Vemos aí uma agitação sem trégua onde todo ser vivo se resume a uma resistência desesperada contra a morte, a um impulso desmesurado e insaciável em vista da conservação da espécie: "É com vistas a esse fim que ela [a natureza] trabalha através de uma superabundância desmesurada de germes, através da violência impaciente do instinto sexual (...)”33, malgrado essa superabundância de impulsos e forças não seja o objetivo da natureza.

Mas se mesmo uma vez por acaso resta um excedente de força por consequência do bem-estar, e além disso, na única espécie dotada de razão, um excedente de conhecimento, é um resultado muito pouco importante para dele fazer a finalidade de toda essa atividade da natureza. ${ }^{34}$

A vontade como princípio que diz de uma tendência desmesurada atuando em todo ser vivente no sentido de buscar prolongar e conservar o mais longamente possível a sua existência, apesar de ser um princípio inexplicável, é, segundo Schopenhauer, o mais capaz de servir como fundamento explicativo do mundo aonde nos encontramos ${ }^{35}$, princípio esse que não resulta de maneira alguma de um conhecimento objetivo do valor da vida, pois o querer-viver, a vontade, não é um fim ao qual todos os seres perseguem, não é uma espécie de objeto em busca do qual eles se lançam, mas antes é pelo quê eles se vêem já de antemão lançados, involuntariamente, como empurrados, impelidos, "empurrados como por uma energia invisível"36. O querer-viver age como um empurrão involuntário que deixa sempre a consciência para trás e a reboque.

\footnotetext{
${ }^{31}$ SCHOPENHAUER, A. WWV/MVR, II, "Caractère du vouloir-vivre”, p. 1079.

32 SCHOPENHAUER, A. WWV/MVR, II, "Caractère du vouloir-vivre", p.1077.

${ }^{33}$ SCHOPENHAUER, A. WWV/MVR, II, "Caractère du vouloir-vivre", p.1078.

${ }^{34}$ SCHOPENHAUER, A. WWV/MVR, II, "Caractère du vouloir-vivre", p.1078.

${ }^{35}$ SCHOPENHAUER, A. WWV/MVR, II, "Caractère du vouloir-vivre”, p.1077.

${ }^{36}$ SCHOPENHAUER, A. WWV/MVR, II, "Caractère du vouloir-vivre”,p.1079. 


\section{BRUNO WAGNER SANTANA.}

A dificuldade é a ausência de um objeto perfeito, o que faz com que mal a vontade seja satisfeita e logo se vê mergulhada no tédio. É então quando vemos se desenhar, assim o diz Schopenhauer, a história trágico-cômica do mundo: a vontade não se move em direção a um objeto que justifique seu desgaste, que a recompense proporcionalmente ao esforço realizado, isto é, que garanta-lhe a satisfação esperada.

Se imaginássemos a raça humana sendo pressionada por reflexões da razão, (...) fazendo esforços rumo a bens que lhe espera, cuja a conquista seria uma recompensa proporcional a seus labores e sofrimentos (...) há muito tempo alguém já teria gritado: "O jogo não vale à pena", e teria abandonado a partida. Mas cada homem, ao contrário, se ocupa de sua vida e a defende como um penhor precioso lhe confiado e posto sob sua estrita responsabilidade, e isso em meio a preocupação inacabáveis e carências constantes, em meio às quais a existência se passa. ${ }^{37}$

A vida é essa trágica repetição da insatisfação da vontade, que tem de se contentar com uma ausência de dor relativa e passageira ${ }^{38}$, saltando de desejo em desejo, sem conseguir eliminar por completo a insatisfação que obstaculiza seu encontro com um objeto perfeito, isto é, com a plenitude. O desejo do desejo seria assim eliminar a si mesmo, superar-se a si mesmo num encontro "perfeito", palavra essa que é sinônimo de "completo"; mas para que isso acontecesse seria preciso que o desejo, a vontade, eliminasse a sua própria condição, isto é, eliminasse o desencontro, a tensão, - a vontade quer eliminar-se a si mesma tal como um corpo sólido busca tornar-se líquido ${ }^{39}$.

\footnotetext{
${ }^{37}$ SCHOPENHAUER, A. WWV/MVR, II, "Caractère du vouloir-vivre",p.1085.

${ }^{38}$ SCHOPENHAUER, A. WWV/MVR, II, "Caractère du vouloir-vivre",p.1084.

${ }^{39}$ A título de hipótese, se partirmos disso que diz Schopenhauer acerca do querer-viver, da vontade de eliminar toda a tensão e por meio disso encontrar satisfação, talvez pudéssemos colocar a seguinte questão: "Tudo o que é sólido se desmancha no ar" - essa frase de Marx, expressa no Manifesto Comunista, é o problema de uma época ou a metade todos os tempos? Estaríamos em vias de realizar essa meta em nossa época atonal, tal como Zîzêk se refere à nossa época, no seu livro Em defesa das causas perdidas? Se partirmos da materialidade do desejo em Schopenhauer talvez pudéssemos responder que sim, em nossa época a vontade parece estar em vias de realizar-se, isto é, de liquidificar-se completamente, espraiar-se num amolecimento geral, desmanchando-se numa multiplicidade que parece tender a se tornar cada vez mais rarefeita, relaxada, anêmica, plana, atualidade líquida de múltiplos pontos moventes onde tudo escorre e nada se erige senão o imperativo: "tu deves transgredir tudo e não deves avaliar nada, não deves ter opinião alguma a não ser a opinião de ser contra tudo e a favor da pura subversão, pois nela, na transgressão, encontrarás toda a felicidade e liberdade!”.
} 
Como a vontade, em todos seus graus de manifestação, do mais baixo ao mais alto, carece totalmente de um fim último, deseja sempre, o desejo sendo todo o seu ser; desejo que não cessa com nenhum objeto alcançado, incapaz de uma satisfação derradeira, e que para parar necessita de um obstáculo, lançada que foi por ela mesma no infinito. É o que verificamos no fenômeno o mais simples da natureza: na gravidade, esforço interminável, e que tende para um ponto central, sem extensão, que ele não poderia atingir sem se anular junto com a matéria; e todavia para isso ele tende e tenderia ainda quando o universo estivesse inteiramente concentrado em uma massa única. $\mathrm{O}$ mesmo pode-se dizer dos outros fatos elementares; todo corpo sólido, seja por fusão, seja por decomposição, tende ao estado líquido, o único onde todas as suas forças químicas estejamem liberdade; a rigidez é como um aprisionamento, onde elas ficam reduzidas pelo frio. O líquido tende ao estado gasoso, para onde ele passa desde que deixa de ser constrangido por alguma pressão. Não há corpo que não tenha uma afinidade, isto é, uma tendência,e, como diria Jacob Boehme, um desejo, uma paixão. A eletricidade, ao infinito, continua a se dividir em dois fluidos, ainda que a massa da terra os absorva. Assim também o galvanismo (...) não é senão um ato que repetesesem cessar e sem fim, em que o fluido se divide contra ele mesmo, e depois se reconcilia. É ainda um esforço muito semelhante, incessante, jamais satisfeito, que toda a existência da planta, um esforço contínuo, através de formas cada vez mais nobres, chegando por fím ao grão, que por sua vez é um ponto de partida; e isso repetido ao infinito. Jamais um final verdadeiro, jamais satisfação final, em parte nenhuma um lugar de repouso. ${ }^{40}$

A não satisfação com o objeto - ou a satisfação incompleta, parcial, insuficiente relança o desejo a outro objeto, mas como nenhum objeto satisfaz completamente o desejo, este então torna-se uma repetição incessante, repetição essa que constitui o infinito, infinito de vontade que não encontra termo final que aliviasse sua tensão, que relaxasse suas forças a tal ponto que elas pudessem encontrar-se completamente livres. A tensão quer desmanchar-se, tudo que é sólido quer liquidar-se, ou seja, encontrar um espaço que fosse inteiramente liso, sem atrito algum, que não oferecesse resistência alguma, que não oferecesse perturbação alguma à plena satisfação da vontade. Ora, esse não poderia ser senão um espaço sem extensão, ponto absoluto de plena positividade, sem margens e divisões, sem início e sem fim, onde não se tivesse que deparar com qualquer resistência oferecida pelo ar, pela água, pela terra ou pelo fogo. A vontade, como tudo o que é sólido, tende a se desmanchar, tende a eliminar tudo o que lhe opõe resistência. Quando a vontade encontra um obstáculo que lhe resiste, eis então o

\footnotetext{
${ }^{40}$ SCHOPENHAUER, A. WWV/MVR I, §56, p. 390-391.
} 
BRUNO WAGNER SANTANA.

sofrimento, a dor; assim como do contrário é a felicidade, o bem-estar ${ }^{41}$. Isso se aplica a todos os seres viventes, portem eles inteligência ou não. Todo desejo nasce de uma falta $^{42}$, e eliminar a falta é justo o que a vontade quer, quer encontrar o reino do liso, reino da plena positividade e satisfação.

Mas se já sabemos onde mora a felicidade, por que desconfiamos que ainda não somos o tanto felizes como gostaríamos de ser? Por que não agimos conforme ajuíza nosso intelecto? Eis o problema conhecido pelos gregos como akrasia; é o que se pergunta Aristóteles referindo-o à mulher, à moleza, isto é, ao problema da incapacidade de resistir, incapacidade de manter-se firme e dominar-se ante os prazeres ou sofrimentos, incapacidade essa que distinguiria o masculino do feminino ${ }^{43}$ : "pode-se perguntar como uma pessoa que tem uma concepção correta das coisas pode ser incontinente em suas ações" "44. A questão para Aristóteles é: já que toda ação visa atingir o um bem ${ }^{45}$, sendo o bem-superior a felicidade ${ }^{46}$ - que não é senão algo final e auto-suficiente, algo que rompe a ligação entre desejo e carência ${ }^{47}$ e liga-o à perfeição ${ }^{48}$ - como a ação de um pessoa que tem consciência disso pode ser contrária ao seu pensamento e por conseguinte contrária à felicidade?

Se a dificuldade para pensar a akrasia em Aristóteles aumenta devido ao fato de ele considerar o desejo como possuindo uma finalidade, que é a felicidade, se partirmos de Schopenhauer poderíamos pensar de maneira diferente o mesmo problema: não possuindo a segurança e a regularidade dos instintos que possuem os animais, os homens agem tantas vezes contrariamente ao que a consciência lhes ordena.

Segundo Schopenhauer, o homem, mais do que qualquer outro animal, dá a ver a dimensão cega, insatisfeita e insaciável da vontade, pois se por um lado a vontade nos animais nunca é também plenamente satisfeita, nestes ao menos há uma regularidade instintual $^{49}$, uma segurança quanto ao objeto, ao passo que no homem não há um saber biológico que faça com que todos os homens encontrem satisfação com um mesmo

\footnotetext{
${ }^{41}$ SCHOPENHAUER, A. WWV/MVR I, §56, p.391-392.

${ }^{42}$ SCHOPENHAUER, A. WWV/MVR I, §56, p. 392.

${ }^{43}$ ARISTÓTELES.Ética a Nicômaco, Livro VII, §7, p. 245.

${ }^{44}$ ARISTÓTELES.Ética a Nicômaco, Livro VII, §2, p. 233.

${ }^{45}$ ARISTÓTELES.Ética a Nicômaco, Livro I, §1, p. 118.

${ }^{46}$ ARISTÓTELES.Ética a Nicômaco, Livro I, §4, p. 120.

${ }^{47}$ ARISTÓTELES.Ética a Nicômaco, Livro I, §7, p. 126.

${ }^{48}$ ARISTÓTELES. Ética a Nicômaco, Livro VII, §13, p. 253.

${ }^{49}$ SCHOPENHAUER, A. WWV/MVR, I, $\$ 54$, p. 358.
} 
objeto, de modo que os seres humanos encontram-se sempre errantes e com uma consciência em constante inquietação em face do caráter insatisfatório dos prazeres que encontra pelo caminho( seja dentro da civilização, essa mascarada, ou fora dela) ${ }^{50}$. Mais do que qualquer outro animal, o homem evidencia na sua errância um mundo dessubstancializado, desarrazoado, luta contínua que possui como aspecto positivo o sofrimento (doença, privação, angústia...), enquanto a felicidade the aparece como sendo algo negativo, isto é, como negação do sofrimento e insatisfação; o homem para Schopenhauer é o animal perverso, o animal mais cruel dentre todos, animal que se vê pressionado a lutar a fim de conservar sua própria existência, e que a fim de aliviar seu próprio padecimento causará a dor dos homens que estão em sua proximidade de convívio. $^{51}$

\section{Referências bibliográficas}

ARISTÓTELES. Ética a Nicômaco. Trad. publicada sob licença da Editora Universidade de Brasília. São Paulo: Nova Cultural (Os Pensadores), 1996.

BRUM, José Thomaz. O pessimismo e suas vontades: Schopenhauer e Nietzsche. Rio de Janeiro: Rocco, 1998.

NIETZSCHE, Friedrich. Crepúsculo dos Ídolos ou como se filosofa com o martelo. Trad. de Paulo César de Souza. São Paulo: Companhia das Letras, 2006.

SCHOPENHAUER, Arthur. Critique de la philosophie kantienne. Traduit en français par A. Burdeau. Paris: PUF, 2006.

SCHOPENHAUER, Arthur. Le monde comme volonté et comme représentation. Traduit en français par A. Burdeau. Paris: PUF, 2006.

SCHOPENHAUER, Arthur. Parerga e Paralipomena. Tradução de Wolfgang Leo Maar e Maria Lúcia Mello e Oliveira Cacciola. São Paulo: Nova Cultural (Os Pensadores), 1988. 